\title{
Determining factors causing disturbance of adaptation mechanisms in residents of radiocontaminated territories in the Ural region
}

\author{
A.N. Varaksin, V.N. Shershnev and V.N. Chukanov \\ Institute of Industrial Ecology, Russian Academy of Sciences, Ural Branch, \\ 20-a S. Kovalevskaya Str., Ekaterinburg 620219, Russia
}

\begin{abstract}
Work was carried out in the East-Ural Radioactive Trace area and the Techa river valley, to which liquid radioactive waste was drained. Data on the state of health and health loss risk factors for residents of these territories were gathered. With regard to the state of health, data are available of clinical examination by a medical specialist, with assessment of the state of organism principal systems (cardiovascular, bonemuscular, nervous, etc.), and data on human organism pre-nosologic indicators. With regard to the risk factors, data are available on single individuals' residence, bad habits, traits of character and way of life, unhealthy work conditions, etc. These data have been entered in a computer database listing 1500 individuals. The present report outlines the results of analysis of the effect of various risk factors on pre-nosologic indicators (indices of the state of human organism adaptation systems). It is shown that, for residents of the Techa river basin, maximum influence on disturbance of adaptation mechanisms ("Regulatory systems activity indicator", or RSAI) is exerted by such factors as: age, water supply characteristic, excessive weight. The fact of living on a radiocontaminated territory has no direct influence on RSAI; however, there are signs of indirect influence of the place of residence on RSAI, which are: varying dependence of RSAI on age in test and control groups, and combined effect of the water supply characteristic and place of residence on RSAI. In case of the inhabitants of the East-Ural Radioactive Trace area, there is revealed a noticeable influence of the accumulated dose on disturbance of adaptation mechanisms. Such influence has been detected within homogeneous population groups picked out by such features as: bad habits, harmful location factors, unfavourable conditions of work, etc.
\end{abstract}

\section{INTRODUCTION}

In 1949, in the north of the Chelyabinsk Oblast (Ural region, Russia), Russia's first industrial complex for plutonium recovery and fission materials processing was commissioned. Later, the "Mayak" Production Association was organized on its base. There were main two radiation incidents in the history of the "Mayak" PA connected with its activity.

1) In the period between 1949-1952 "Mayak" disposed of radiochemical production wastes of about 2.7 million $\mathrm{Ci}$ total activity to the Techa river which presents part of the Iset-Tobol-Irtysh$\mathrm{Ob}$ river system (the river $\mathrm{Ob}$ falls into the Arctic Ocean). The Techa and Iset river valleys underwent radioactive pollution, with the highest degree of radiocontamination in the upper reaches of the Techa river. As a result, 124 thousand people in the Chelyabinsk and Kurgan Oblasts living along the banks of these rivers were exposed to irradiation [1].

2) Due to violation of the rules for safe handling of liquid radiochemical production wastes, an explosion of a container with highly radioactive waste occurred in 1957 . About 20 million Ci were released into the environment, of which 2 million $\mathrm{Ci}$ were scattered by the wind in the NE direction. As a result, part of the territories of the Sverdlovsk and Chelyabinsk Oblasts was contaminated, and the affected territory received the name of the East-Ural Radioactive Trace (EURT). The contaminated the territory of about 1 thousand sq. $\mathrm{km}$ had over $2 \mathrm{Ci}$ per sq. $\mathrm{km}$ in Strontium-90. About 300 thousand people were affected by radioactive irradiation[1].

The purpose of this paper, which presents the first part of the investigation, is to assess the effect of radiocontamination of the territory and of other risk factors on health of the population living in the area of the Techa river. The second part describes a similar investigation carried out in the EURT zone.

The state of health was assessed by the so-called pre-nosologic indicators [2-4]. The concept of pre-nosologic diagnostics is based on the assumption that between the "healthy" and "sick" states 
there exists a series of intermediate states which are termed "pre-nosologic" states, and the indicators describing these states are called pre-nosologic indicators.

In case the effect of the investigated pathogenic factor is not excessive and does not lead explicitly to concrete diseases, then registration of changes in human organism at the level of prenosologic states appears to be more sensitive than registration of clearly defined pathologies only.

\section{THE RIVER TECHA BASIN}

This investigation was expected to give answers to the following main questions:

- are there any significant differences in pre-nosologic indicators in residents of the villages located on the banks of the Techa river and those living on the clean territory?

- if there are differences, what is the informative set of indicators which allows to describe such differences?

- which risk factors (environment radioactive pollution, way of life, specific features of an organism etc.) have the greatest negative effect on pre-nosologic indicators?

\subsection{Starting Material and Formulation of the Problem}

The investigation involved adult population (18 years and older) living in the "test" and "control" populated areas. The selected "test" (radiocontaminated) populated areas were villages Verkhnaya Techa, Kazantsevo, Anchugovo located in the basin of the Techa river 170-200 km downstream of the point of radioactive wastes release. The "control" (clean) area was village Koryukovo located at a distance of about $30 \mathrm{~km}$ from the Techa river and having similar climatic and daily life conditions.

During field trips of 1993-1995 data were gathered of pre-nosologic indicators in 443 patients currently living in the test area, and 193 patients living in the clean zone (control area). Prenosologic indicators were gathered with the use of a software and hardware complex designed at the Institute of Industrial Ecology, Ural Branch of Russian Academy of Sciences [5]. The list of pre-nosologic indicators is given in Table 1. They are divided in two sets: the first one includes hemodynamic and height-and-weight indicators, the second one presents human cardiac rhythm indicators; the last one on the list (the regulatory systems activity indicator, or RSAI) presents an integral characteristic showing the degree of adaptation mechanisms disturbance in human organism. It varies from 0 to 10 points; the values of RSAI $=(0-1)$ correspond to the norm, RSAI $=(9-10)$ to failure of adaptation, while the values of RSAI between 2 and 8 correspond to different degrees of adaptation mechanisms disturbance.

Selection with the use of the "case-control" method (one patient from the test group, the other one from the control group) allowed to establish 72 pairs among the female populations similar in age and bad habits (smoking and alcohol drinking). Besides, in establishing such pairs, permanent (from the date of birth) female residents of one settlement were selected.

In case of men-patients, the attempt to establish a sufficient number of pairs similar in age and bad habits - with observation of the condition of permanent residence in one and the same settlement - failed; therefore the idea of analyzing male population was abandoned.

Three types of investigations were carried out for the selected 144 women-patients: 1 - analysis of mean-value differences of pre-nosologic indicators in the test and control groups (statistical analysis carried out separately for each indicator in Table 1);2-creating a generalized multi-factor "image" of an inhabitant of the contaminated (test) and clean (control) territories; 3 - analysis of the effect of various risk factors on one of the integral pre-nosologic indicators - the regulatory systems activity indicator. 


\begin{tabular}{|c|c|}
\hline $\begin{array}{c}\begin{array}{l}\text { Order } \\
\text { No. }\end{array} \\
\end{array}$ & Indicators \\
\hline \multicolumn{2}{|r|}{ Hemodynamic and Height-and-Weight Indicators Set } \\
\hline 1 & Pulse pressure (difference between systolic and diastolic pressures) \\
\hline 2 & Stroke blood volume \\
\hline 3 & Minute blood volume \\
\hline 4 & Mean dynamic pressure \\
\hline 5 & Vessels peripheral resistance (VPR) \\
\hline 6 & Double product \\
\hline 7 & Orthostatic stability Index \\
\hline 8 & Systolic index \\
\hline 9 & Brock index (human weight - height +100 ) \\
\hline 10 & Kettle index (human weight / height \\
\hline 11 & Functional changes index \\
\hline \multicolumn{2}{|r|}{ Cardiac Rhythm Indicators Set } \\
\hline 12 & Pulse rate (mean value of set of cardio-intervals) \\
\hline 13 & Standard deviation of set of cardio-intervals \\
\hline 14 & Variance range of set of cardio-intervals (VR) \\
\hline 15 & Variation coefficient of set of cardio-intervals \\
\hline 16 & Mode amplitude of set of cardio-intervals \\
\hline 17 & Stress index \\
\hline 18 & Number of Autocorrelation Function Shifts to first negative value \\
\hline 19 & Spectrum (respiratory waves) \\
\hline 20 & Spectrum (slow waves) \\
\hline 21 & Spectrum (higher order slow waves) \\
\hline 22 & $\begin{array}{l}\text { Summary regulatory effect }(=0, \pm 1, \pm 2 \text {, where } 0 \text { is the norm, } \pm 1, \pm 2 \text { are moderate and clearly } \\
\text { defined deviations from the norm) }\end{array}$ \\
\hline 23 & Automatism function $(=0, \pm 1, \pm 2$, same as p.22) \\
\hline 24 & Vegetative homeostasis $(=0, \pm 1, \pm 2$, same as p.22) \\
\hline 25 & Regulation stability $(=0, \pm 1, \pm 2$, same as p.22) \\
\hline 26 & Subcortical nerve centres activity $(=0, \pm 1, \pm 2$, same as p.22) \\
\hline 27 & $\begin{array}{l}\text { Regulatory systems activity indicator (RSAI) equal to sum of absolute values of indicators from } 22 \text { to } \\
26 \text {. }\end{array}$ \\
\hline
\end{tabular}

\subsection{Analysis of Statistical Significance of Mean-Value Differences}

For each of the 27 pre-nosologic indicators (Table 1), comparison of mean values of indicators for residents of the test and control groups was carried out. Use was made of Student t-test and Wilcoxon non-parametric criterion. Statistically significant differences $(p<0.5)$ were revealed for two parameters only: vessels peripheral resistance (VPR) and variance range (VR).

Let us consider close the VPR and VR parameters. According to our data for the control group (clean territory), mean value of VPR $=955$ dyne.s $/ \mathrm{cm}^{5}$ and for the test group (contaminated territory), mean value of VPR $=1058$ dyne.s $/ \mathrm{cm}^{5}$. In the present day knowledge, the rise in the value of VPR is connected with loss of elasticity of vascular wall, vascular sclerosis, i.e. it testifies to negative changes in human organism taking place, e.g., at person's ageing [6]. Since in our investigation the test and control groups were of the same age, the rise in the value of VPR in the

test group was due to some additional negative factors affecting the test group population; one of such possible factors is environment radioactive pollution.

Similar to rise in the value of VPR at transition from control to test group, the negative changes are also observed in other hemodynamic parameters: rise of mean dynamic and pulse pressure, drop of 
systolic index, and decrease in minute and stroke blood volumes. Even though significant, the changes in hemodynamic indicators in general reflect health loss in the test group population.

The second parameter revealing the difference between the test and control groups is the variance range (difference between the maximum and minimum values of cardio-intervals in the pulse diagram). It describes the level of cardiac rhythm instability and is connected with the vegetative homeostasis indicators. It is known $[2,3]$ that both the small and the big values of variance range are regarded as indicators of health negative changes. Normally, the variance range takes a value in the interval of $(0.17-$ 04.) $s$ [4]. According to our data, the VR mean value in the control group was $0.30 \mathrm{~s}$, which is in compliance with the norm; in the test group the value of VR was 1.5 times slammer $(0.20 \mathrm{~s})$, which presents the norm lower limit.

\subsection{Creating a Generalized "Image" of an Inhabitant of Test and Control Groups}

The above single-factor analysis of differences between the test and control groups may be supplemented with a multi-factor analysis using the discriminant analysis methods. In case of such analysis the problem is formulated as follows: is there a difference between pre-nosologic indicator sets in the test and control group populations? It may be asserted in case off a positive answer that the place of residence (possibly the territory radiocontamination) influences the health indicators set; it is possible also to list the most informative set of indicators which allows to discriminate between the inhabitants of these territories.

In the problem solution use was made of the method of linear discriminant function (Fisher's linear model [7]) and its software implementation in package "Statistica for Windows". The starting set of indicators is given in Table 1 . The procedure of selecting the most informative set of indicator was the following. Indicators with the least value of standardized coefficient $a_{\mathbf{n}}$ of linear discriminant function were removed from the complete set. If, after the indicator removal, the percentage of correct discrimination between inhabitants of the test and control territories became higher, then the given indicator was regarded as removed from the set; if otherwise, the indicator was restored, and another indicator with the next minimum $a_{n}$ was removed. Proceeding with this method, we found a set of 9 indicators (Table 2), which yielded acceptable percentage of correct discrimination: $76 \%$ correct discrimination in general and $74 \% / 79 \%$ correct discrimination in the test and control group populations.

Table 2: Informative Set of Indicators and Discriminant Function Standardized Coefficients

\begin{tabular}{|c|l|c|}
\hline Order $\mathbf{N}^{\circ}$ & \multicolumn{1}{|c|}{ Indicator } & Standardized coefficient $\mathbf{a}_{\mathbf{n}}$ \\
\hline 1 & Pulse pressure & +0.34 \\
2 & Minute blood volume & -1.20 \\
3 & Mean dynamic pressure & -1.79 \\
4 & Vessels peripheral resistance & +0.47 \\
5 & Double product & +1.18 \\
6 & Systolic index & +1.69 \\
7 & Brock index & +1.17 \\
8 & Functional changes index & -0.13 \\
9 & Stress index logarithm & -0.27 \\
\hline
\end{tabular}

Thus for discriminating between female population of radiocontaminated territories in the Techa river basin and that on clean territories one can resort to 9 indicators only (out of the complete set of 27 indicators). The determinant rule used in discrimination has the following form: if $Z>0$, then the resident belongs to the test group; if $Z \leq 0$, the resident bclongs to the control group, where $Z=a_{1} X_{1}+a_{2} X_{2}+\ldots+$ $a_{n} X_{n}$ is linear discriminant function, $X_{n}$ are pre-nosologic indicators; $a_{n}$ are coefficients from Table 2 . 


\subsection{Analysis of Influence of Risk Factors on Regulatory Systems Activity Indicator (RSAI)}

This section describes investigation of the influence of various risk factors on adaptation mechanisms disturbances (RSAI parameter) in the Techa river basin and the control territory residents. Among such factors, the person's age, place of residence (possibly the territory radiocontamination), water supply characteristic, excessive weight, meteotropic reactions, insomnia, psychologic stress in family, work in the garden were considered.

1. Age. As was expected, the RSAI parameter value increases with age, i.e., with age the degree of strain on the adaptation mechanisms grows. The simple linear regression method shows that, on the average, the RSAI value increases by 0.09 points every 10 years of person's life. This is a very small and statistically insignificant value $(p>0.05)$. If, however, we pick the inhabitants older than 40 years of age (born before radioactive waste was first drained in the Techa river), the RSAI value increase rises to 0.4 points per every 10 years of life and thus becomes statistically significant $(p=0.025)$. Analysis of influence of other factors on RSAI was carried out for the inhabitants that were older than 40 as of the moment of examination.

2. Place of residence. For the test group, the mean value of RSAI $=2.18$; for the control group, the value was slightly smaller: $\mathrm{RSAI}=1.85$, with the difference between the two being statistically insignificant. Hence, no direct influence of the place of residence (possibly the territory radiocontamination) on $\mathrm{RSAI}$ values was detected.

The following fact testifies to presence of indirect influence on RSAI: when investigation of the dependence of RSAI on age (similar to investigation carried out under p.1) was arranged separately for the populations of the test and control groups, RSAI value grew to 0.69 points per 10 years of life in the test group, and stayed close to zero in the control group.

3. Water supply characteristic. Residents of the investigated territories obtain drinking water from two sources: water mains (centralized water supply with water treatment) and wells. Comparison of RSAI mean values for the inhabitants using water from mains and those using wells shows no statistically significant difference.

Analysis of combined influence of the place of residence and the water supply characteristic on RSAI was carried out using the method of two-factor analysis of variance with account for crosseffects. It was found that for the clean (control) territory transfer from water main to well water decreases RSAI from 2.44 to 1.48; at the same time, the situation is reversed for the test (radiocontaminated) territory: transfer to well water increases RSAI from 2.00 to 2.52 at the same mean age values of inhabitants in all groups. As a result, the cross-effect of combined influence of the place of residence (test, control groups) and water supply characteristic (water main, well) on RSAI values becomes statistically significant $(p=0.04)$.

Such an effect may be given logical explanation. In principle, well water in Russia is more favourable for health, which is confirmed by the data for the control territory. Water on the test territory contains (or earlier contained) some harmful components (probably, radioactive isotopes) which are detrimental to human health.

4. Excessive weight. No statistically significant difference was noted in RSAI mean values for women with normal and excessive weights $(p=0.09)$; however, the negative effect of excessive weight on RSAI is well observed: in the control group mean values of RSAI $=1.77$ for women with normal weight and RSAI $=2.43$ for women with excessive weight; in the test group the differences is even greater: $\mathrm{RSAI}=2.12$ and 3.33 , respectively. The reason explaining absence of statistically significant difference in RSAI values for women with normal and excessive weights was the small number of women with excessive weight in the investigated sample ( 7 women in the control group and 6 in the test group).

In a similar manner the influence of such factors as "meteotropic reactions", "insomnia", "psychologic stress in family", "work in the garden" on RSAI was investigated. None of these parameters has any significant influence on the RSAI parameter.

At the final stage of investigation an attempt was made to describe (predict) the RSAI parameter values in terms of all the above-mentioned parameters simultaneously, based on the covariance model (section General Linear Model - General MANOVA/MANCOVA in package Statistica for Windows). The model takes into account single-factor effects and only dual crosseffects of such factors as water supply characteristic, excessive weight, meteotropic reactions, 
insomnia, psychologic stress in family, work in the garden, and the factor "Place of residence". Parameter "Age" was used as a continuous independent variable.

As it was expected from the above results, in the covariance model, parameter "Age" and cross-effect "Place of residence - Water supply characteristic" exert statistically significant influence in RSAI; besides, parameter "Excessive weight" appeared to be a statistically significant factor $(\mathrm{p}=0.017)$ in the covariance model. The determination coefficient in the covariance model is $R^{2}=0.175$. Despite the fact that the obtained value of $R^{2}$ differs statistically significantly from zero $(p<0.05)$, its small numerical value points to existence of some unaccounted for factors exerting strong influence on the RSAI parameter.

\section{CONCLUSIONS}

Comparison was carried out of pre-nosologic diagnostics indicators in the population living near the Techa river (radiocontaminated territory) and in the control (clean) region. Statistically significant differences were found for the indicators "Vessels peripheral resistance" (hemodynamics indicator) and "Variance range" (cardiac rhythm indicator). Both indicators testify to unfavourable shifts in the organisms of residents of contaminated territories. Earlier, acceleration of ageing rates was detected in the inhabitants of the Techa river basin [8].

It was shown that multi-factor "image" of residents in the test group differs from same on the control territory; high percentage of correct discrimination between residents in the test and control groups may be obtained through use of nine pre-nosologic indicators.

Factors exerting maximum influence on the "Regulatory systems activity indicator", or RSAI, were found. They are: age, water supply characteristic, excessive weight. The fact of living on a radiocontaminated territory has no direct influence on RSAI; however, there are signs of indirect influence of the place of residence on RSAI, which are: varying dependence of RSAI on age in test and control groups, and combined effect of the water supply characteristic and place of residence on RSAI.

\section{Acknowledgements}

This work was supported by the Russian Federal Program "Integration".

\section{References}

[1] Chukanov V.N., Volobuev P.V., Drozhko E.G. et al. Genesis and Concepts of State Program of the Russian Federation of Radiation Rehabilitation of the Ural Region and Measures to Support the Suffered Population for the Period until 1995 (Institute of Industrial Ecology of UB RAS Publishers, Ekaterinburg, 1993).

[2] Baevskii R.M. Prediction of Boundary States Between Normal and Pathologic (Meditsina, Moscow, 1979).

[3] Baevskii R.M., Kirillov O.I. and Kletskin S.Z. Mathematical Analysis of Cardiac Rhythm Changes under Stress (Nauka, Moscow, 1984).

[4] Kaznacheev V.P., Baevskii R.M. and Berseneva A.P. Pre-Nosological Diagnostics in the Practice of Mass Examinations of Population (Meditsina, Leningrad, 1980).

[5] Chukanov V.N., Gorbich L.G., Zhivoderov A.A. and Varaksin A.N. Hardware and Software Complex "VITA-MARS" for Mass Pre-Nosologic Investigations of Population Health. Ekologicheskiye systemy i pribory (Russian J. Ecological Systems and Instruments, Moscow). 2 (1999) 21-23.

[6] Frolkis V.V., Bezrukov V.V. and Shevchuk V.G. Blood Circulation and Ageing (Nauka, Leningrad, 1984).

[7] Afifi A.A. and Azen S.P. Statistical Analysis. A Computer Oriented Approach (Academic Press, New York-San Francisco-London, 1979).

[8] Polzik E.V., Lemyasev M.F., Varaksin A.N. et al. To the Problem of Assessment of Radiation Influence on the Processes of Ageing of Resident Population of the Techa River Area. Gigiena $i$ sanitariva (Russian J. Hvgiene and Sanitarv. Moscow). 1 (1995) 25-27. 